\title{
COMPARATIVE STUDY BETWEEN INTRAVENOUS IRON SUCROSE AND ORAL IRON FOR TREATMENT OF POST PARTUM ANEMIA
}

Samta Gupta ${ }^{1}$, Shelly Agarwal2 ${ }^{2}$ Nimmi Chuttani' ${ }^{3}$, S. S. Gulati ${ }^{4}$

\section{HOW TO CITE THIS ARTICLE:}

Samta Gupta, Shelly Agarwal, Nimmi Chuttani, S. S. Gulati. "Comparative Study between Intravenous Iron Sucrose and Oral Iron for Treatment of PostPartum Anemia". Journal of Evolution of Medical and Dental Sciences 2014; Vol. 3, Issue 10, March 10; Page: 2497-2503, DOI: 10.14260/jemds/2014/2163

ABSTRACT: AIMS \& OBJECTIVES: The aim of study was to compare the efficacy, safety and compliance of intravenous iron sucrose complex with oral Iron therapy in treatment of postpartum anemia. MATERIAL AND METHODS: 60 postpartum women who had delivered within 24 -48 hours and having hemoglobin $<9.0 \mathrm{gm}$./ $\mathrm{dl}$ and serum ferritin $<15 \mu \mathrm{g} / \mathrm{L}$ were studied prospectively. They were randomized into two groups. In Group A 30 women received $200 \mathrm{mg}$ of iron sucrose on every alternate day for 3 days and in group B 30 women received oral iron ferrous sulphate tablets twice daily for 30 days. Hemoglobin and serum ferritin were measured on day 7, and day 30 . The side effects in both groups were noted. RESULTS: There was a significant rise in mean hemoglobin on day 7 in intravenous iron group (7.23 \pm SD $0.57 \mathrm{gm}$./ $\mathrm{dl}$ to $9.24 \pm \mathrm{SD} 0.57 \mathrm{gm} . / \mathrm{dl})$ in comparison to oral iron (7.33 \pm SD $0.41 \mathrm{gm} . / \mathrm{dl}$ to $7.42 \pm$ SD 0.39.) difference was statistically significant (p value $<0.01$ ) Mean Hemoglobin on day 30 was higher in Intravenous iron group than oral iron although the difference was not significant. Mean serum ferritin levels showed rise from $11.40 \pm$ SD $0.94 \mu \mathrm{g} / \mathrm{L}$ to $40.42 \pm 7.76 \mu \mathrm{g} / \mathrm{L}$ in Intravenous iron group on 7 th day and it was $49.21 \pm 3.33 \mu \mathrm{g} / \mathrm{L}$ on day 30.Level of rise on day 30 of serum ferritin in intravenous was significant $(\mathrm{p}<0.001)$ whereas in oral iron group on day 30 mean Serum ferritin was $15.86 \pm 2.28 \mu \mathrm{g} / \mathrm{l}$ level of rise was not significant (p value $>$ 0.05). Intravenous iron sucrose did not result in any serious adverse reactions. CONCLUSION: Intravenous iron sucrose is more effective, rapid and safe in increasing hemoglobin level in women with postpartum anemia in comparison with oral iron therapy. It also replenishes iron stores more rapidly without any serious adverse effects.

KEYWORDS: Post-partum anemia, intravenous iron sucrose, oral ferrous sulphate.

INTRODUCTION: Approximately $80 \%$ of all anemia's in pregnancy result from iron deficiency. ${ }^{1}$

Anemia is the commonest cause of maternal mortality and morbidity in India. In India maternal mortality has been reported to be $19 \%$ due to anemia. The prevalence of anemia in world population is estimated between $20-50 \%$. Incidence of anemia in pregnancy varies from $14 \%$ in developed to $51 \%$ in developing countries. In India its incidence is $65 \%-75 \% .^{2}$ According to WHO $56 \%$ women suffer postpartum anemia. ${ }^{3}$

High prevalence of iron deficiency is due to faulty dietetic habit, faulty absorption mechanism, increased iron loss as consequence of repeated pregnancies at short intervals, excessive blood loss during menstruation, hookworm infestation and chronic malaria. ${ }^{4}$

Postpartum iron deficiency is associated with fatigue, physical disabilities, postpartum blues, reduced cognitive abilities ${ }^{5}$ and significant health problems in women of reproductive age. Neonatal effects can be anemia in new born \& failure to thrive due to maternal ill health. If untreated, the woman will start the next pregnancy with iron deficit increasing the morbidity and mortality in pregnancy. Hence it is important to treat postpartum anemia. 
The standard approach to treatment is oral iron supplementation, with blood transfusion reserved for more severe or symptomatic cases. Although blood transfusion can promptly and reliably treat anemia, there are a number of hazards of blood transfusion including transfusion of the wrong blood, infection, anaphylaxis and lung injury, any of which could be life threatening for a young mother. Because of these hazards, and shortage of blood products, transfusion should be viewed as a last resort in otherwise young and healthy women. ${ }^{6}$ Oral iron supplementation is more commonly used than blood transfusion for postpartum IDA. However, it is unreliable in the treatment of severe anemia due to its limited absorption and gastrointestinal adverse effects that affect compliance. ${ }^{8,9}$ Parenteral iron therapy by intramuscular injection of iron dextran was earlier used but is painful and is associated with a significant risk of anaphylactoid reactions in 0.6 to $2.3 \%$ of patients $7,8,9$ Parental iron administration with ferrous sucrose is now available and can be safely used for treatment of iron deficiency anemia in postpartum period ${ }^{10}$. So the following study was conducted to compare the efficacy and safety of intravenous iron sucrose with oral iron in treatment of postpartum anemia.

MATERIAL AND METHODS: This prospective randomized study was conducted in Dept. of Obstetrics \& Gynecology at School of Medical Sciences \& Research Sharda Hospital Greater Noida from Jan 2013 to June 2013.

Study population: 60 postpartum women aged $>18$ years at $24-48$ hours of delivery having hemoglobin $<9 \mathrm{gm} . / \mathrm{dl}$ and serum ferritin $<15 \mu \mathrm{g} / \mathrm{L}$ were included in the study. Written informed consent from all women was obtained prior to participation in the study.

Women with Anemia not linked to iron deficiency, hypersensitivity/intolerance to oral or parenteral iron, liver or renal disorders, acute infections, peripartum blood transfusion or a history of asthma, thromboembolism, seizures, alcohol or drug abuse were excluded from study. All women were lactating and had amenorrhea during the study period.

After careful history taking, clinical examination, excluding other types of anemia's with investigations patients were allocated into two groups of 30 each

Group A (study group) - received intravenous iron sucrose. Total dose administered was 600mg in three divided doses of $200 \mathrm{mg}$ each on day 1, 3, 5. 200mg iron sucrose (2 ampoules of $100 \mathrm{mg}$ ) was diluted in $200 \mathrm{ml}$ normal saline and infused over a period of one hour.

Group B (study group) - received oral ferrous sulphate $200 \mathrm{mg}$ twice daily for 4 weeks.

All the patients were supplemented with $5 \mathrm{mg}$ of folic acid to eliminate effects of folic acid deficiency.

Blood samples were taken on day0 and at days 7, and 30 after the start of the treatment. These time-points were chosen based on previous studies. Hemoglobin and Serum Ferritin were estimated and recorded on days chosen in both the groups. Side effects of both oral \& intravenous iron were recorded. Compliance in oral group was assured by asking color of stools and checking the empty packets of iron tablets given at time of discharge.

The statistical-analysis was performed using paired t-test. Variations of $\mathrm{P}<0.05$ were considered to be statistically significant. 
RESULTS: Table 1 shows that maximum number of women was in age group 20-25 years (56.7\%). Around $31.7 \%$ of women belonged to age group $25-30$ years. $6.7 \%$ of women were in between 30 35 years. Only 3\% were $>35$ years. Anemia is more prevalent in age group 20-30 years. 61\% were primipara. 85\% were unbooked and belonged to rural background Changes in Hemoglobin levels (Table 3, 4).

As per Table 2 maximum number of women had hemoglobin in range 6.6-7.5 g/dl before initiation of therapy. The baseline mean hemoglobin in Group A (i.v. iron) before treatment was $7.23 \pm 0.57 \mathrm{~g} / \mathrm{dl}$ and baseline mean Haemoglobin level in the oral iron therapy group was $7.33 \pm 0.41$ $\mathrm{g} / \mathrm{dl}$. After 7 days there was a rise in mean Haemoglobin in the Intravenous iron group from $7.23 \pm 0.57 \mathrm{~g} / \mathrm{dl}$ to $9.24 \pm 0.57 \mathrm{~g} / \mathrm{dl}$ ( $\mathrm{p}$ value $<0.01$ ) which was significant whereas in oral iron group mean Haemoglobin on day 7 was $7.42 \pm 0.39$ ( $p$ value $>0.05$ ). After completion of treatment on day 40 mean haemoglobin in oral group was $10.33 \pm 0.38$ and mean haemoglobin in Intravenous group was $11.24 \pm 0.53$ which was higher than oral group but not statistically significant than oral iron group.

\section{Changes in serum ferritin levels (Table 3,4 )}

The mean Serum ferritin levels before treatment in Intravenous iron group was $11.40 \pm 0.94$ $\mu \mathrm{g} / \mathrm{L}$ and in oral iron group $11.35 \pm 0.91 \mu \mathrm{g} / \mathrm{L}$. On day 7 there was a rise in ferritin levels in Intravenous iron group to $40.42 \pm 7.76 \mu \mathrm{g} / \mathrm{L}$ and in oral iron group to $14.17 \pm 1.098 \mu \mathrm{g} / \mathrm{L}$. Rise was significant in Intravenous group. After end of treatment Serum ferritin levels in Intravenous iron group was $49.21 \pm 3.33 \mu \mathrm{g} / \mathrm{L}$ and in oral iron group $15.86 \pm 2.28 \mu \mathrm{g} / \mathrm{l}$ ( $\mathrm{p}$ value $<0.01$ ) which was statistically significant.

Table 5 shows there were no serious adverse events. In group A, two women (6.7\%) complained of rashes, and 1 had hypotension which was managed conservatively. There were no anaphylactic reaction observed either during infusion or after infusion. In group B, adverse effects were all of a gastrointestinal nature ranging from epigastric pain, nausea and constipation. Despite these symptoms, $100 \%$ compliance was reported and confirmed at the pill counts.

DISCUSSION: Anemia in the postpartum period may be associated with an increased prevalence of breathlessness, tiredness, palpitations and maternal infections, particularly of the urinary tract Such symptoms may cause women to experience difficulty caring for their baby, and may influence the emotional bond the mother has with her baby. Treatment of Post-partum anemia is very important to build up iron reserves in the peurpera, to have a better quality of life and to minimize incidence of anemia in next pregnancy.

So the following study was done to see whether giving iron by Intravenous route in form of ferrous sucrose to women with postpartum anemia results in higher Hemoglobin concentrations and improved iron stores than using standard treatment with oral iron. In our study in study group iron sucrose injection $600 \mathrm{mg}$ in three divided doses of $200 \mathrm{mg}$ (diluted in normal saline) were given on day 1, 3, 5. And Group B received oral ferrous sulphate $200 \mathrm{mg}$ twice daily for 4 weeks. hemoglobin \& Serum. Ferritin (measure of iron stores) were measured on day 0, day7 and day 30. There was a rise in mean hemoglobin in the Intravenous iron group from $7.23 \pm$ SD $0.57 \mathrm{~g} / \mathrm{dl}$ to $9.24 \pm \mathrm{SD} 0.57 \mathrm{~g} / \mathrm{dl}(\mathrm{p}$ value $<0.01$ ) after 7 days. Whereas mean hemoglobin in oral group changed from $7.33 \pm$ SD $0.41 \mathrm{~g} / \mathrm{dl}$ to $7.42 \pm$ SD 0.39 on day 7 . So, it is evident there is early rise of hemoglobin level in Intravenous iron 
group and oral group had no significant improvement in 7 days. On day 30 mean hemoglobin in Intravenous group and oral group was $11.24 \pm$ SD0.53 and $10.33 \pm$ SD0.38 respectively

Westad et al ${ }^{11}$ reported a similar rise in hemoglobin level from baseline of $6.5 \mathrm{gm} / \mathrm{dl}$ to $11.9 \pm 1$ gm./dl after 4 weeks of treatment with Intravenous Iron sucrose $600 \mathrm{mg}$ in 59 postpartum patients. In a similar study by Dede et al 12 on 50 postpartum women there was a rise in hemoglobin level from baseline of $8.2 \pm 0.6 \mathrm{gm} . / \mathrm{dl}$ to $12.5 \pm 1.6 \mathrm{gm} . / \mathrm{dl}$ after 4 weeks. Bayoumeu et al ${ }^{13}$ also reported rise in hemoglobin from $9.6 \pm 79 \mathrm{gm} / \mathrm{dl}$ to $11.11 \pm 1.3$ in Intravenous group and from $9.7 \pm .5$ to $11.0 \pm 1.25$ in oral group at day 30. However Bhandal $\mathrm{N}$ and Russel $\mathrm{R}^{14}$ on day 40 after treatment found no difference in hemoglobin levels between the two groups.

Serum. ferritin was used as indicator of iron storage. There was a rise in Serum ferritin to $40.42 \pm 7.76 \mu \mathrm{g} / \mathrm{L}$ from $11.40 \pm 0.94 \mu \mathrm{g} / \mathrm{L}$ on day 7 in Intravenous group indicating a very rapid rise and on day 30 it was $49.21 \pm 3.33 \mu \mathrm{g} / \mathrm{L}(\mathrm{p}<.001)$. Whereas in oral group there was a rise from baseline of $11.35 \pm 0.91 \mu \mathrm{g} / \mathrm{L}$ to just $15.86 \pm 2.28 \mu \mathrm{g} / \mathrm{l}$ in 30 days.

Bhandal and Russel ${ }^{14}$ also reported a statistical significant increase in Serum. ferritin levels from the baseline values of $13 \mathrm{microgm} / \mathrm{dl}$ to $42.2 \mathrm{microgm} / \mathrm{dl}$ on day 40 in Intravenous iron group. Similar significant rise was observed by Breyman et al.,15 Momen et al.,16, Bayoumeu et al.,13 and Giannoulis $\mathrm{C}$ et $\mathrm{al}^{17}$ with the iron sucrose group. Iron sucrose appears to be effective because it is rapidly removed from the plasma and used for erythropoiesis. 24 hours after administration, the plasma level is negligible, indicating rapid incorporation. There was no case of anaphylactiod reaction in study group indicating its safety. Bayoumeu et al ${ }^{13}$ in his study also suggested that the Intravenous iron sucrose tolerance seemed to be excellent without adverse side effects The high tolerance of the drug has been partly attributed to slow release of iron from the complex and also due to the low allergenicity of sucrose. In oral group the side effects were mainly gastrointestinal related. Momen et al. ${ }^{16}$ and Bhandal and Russel ${ }^{14}$ described gastrointestinal adverse effects with a frequency of up to $30 \%$ and $33 \%$ in women treated with oral iron. In our study $36.7 \%$ had similar GI side effects. So, iron sucrose is an excellent alternative in patients with poor compliance to oral iron. However two factors limit its use, firstly its cost and secondly hospital stay. Hospital stay is beneficial to patient in having fast recovery and better compliance.

CONCLUSION: Previously the main stay of management of postpartum anemia was oral iron or blood transfusion. Blood transfusion increases risks of transmission of HIV and Hepatitis and should be reserved for women with hemodynamic instability, so an alternative method was needed to avoid the need for transfusion.

Intravenous iron sucrose administration increases the hemoglobin level more rapidly than oral intake of ferrous sulphate in women with iron deficiency anemia. It also replenishes iron stores more rapidly than oral iron and is safe and well tolerated. Thus, Intravenous iron sucrose is an effective, convenient, and safe route to cure postpartum anemia in comparison to oral iron supplementation.

\section{REFERENCES:}

1. Fernando Arias, Practical guide to high risk pregnancy and delivery, 2nd edition, p.245.

2. Kalaivani K. Prevalence and consequences of anemia in pregnancy, Indian Journal of Medical Research 2009; 130: 627-633. 


\section{ORIGINAL ARTICLE}

3. World Health Organisation (1992). The prevalence of anaemia in women a tabulation of available information Second edition Geneva (WHO/MCH/MSM -92.2).

4. Dutta DC. Medical illness complicating pregnancy. Textbook of Obstetrics, $6^{\text {th }}$ edition. [Ed Konar H] The central Book Agency Pvt Ltd. Calcutta: 2004; p262- 271.

5. Milman N. Postpartum anemia II, Prevention and Treatment. Annals of Haematology 2012; 91s: 143-54.

6. Morrison JC, Morrison FG. Rational use of blood products in obstetrics and gynecology. J Matern Fetal Invest 1994; 4:147-53.

7. Burns DL, Mascioli EA, Bistrian BR. Parenteral iron dextran therapy: a review. Nutrition 1995; 11: 163-168.

8. Fishaemoglobinane S, Ungureanu VD, Maesaka JK et al. The safety of intravenous iron dextran in hemodialysis patients. Am J Kidney Dis. 1996; 28: 529-534.

9. Hamstra RD, Block MH, Shocket AL. Intravenous iron dextran in clinical medicine. JAMA 1980:243:1726-1731.

10. Scott B. Silverstein, George Rodgers. Parenteral iron therapy options. American Journal of Hematology, 76:74-78(2004).

11. Westad S, Backe B, Salvesen KA, Nakling J, Okland I, Borthen I, Rognerud Jensen OH, Kolas T, LokvikB, Smedvig E. A 12- week randomized study comparing intravenous iron sucrose verses oral ferrous sulphate for treatment of postpartum anemia. Acta Obstet Gynecol Scand. 2008;87(9):916-23.

12. Dede A, Uygur D, Yilmz B, Mungan T and Ugur M. Intravenous iron sucrose complex vs. Oral ferrous sulphate for postpartum iron deficiency anemia. International Journal of Gynaecology and Obstetrics 2005; 90: 238-239.

13. Bayoumeu F, Subiran-Buisset C, BakaNE, Legagneur H, Monnier- Barbarino P, Laxenaire MC. Iron therapy in iron deficiency anemia in pregnancy: Intravenous route versus oral route. Am J Obstet Gynecol; 2002: 186:3: 518-522.

14. Bhandal N, Russell R. Intravenous versus oral iron therapy for postpartum anaemia. BJOG 2006; 113: 1248-1252.

15. Breymann C. Treatment of iron deficiency anaemia in pregnancy and postpartum with special focus on intravenous iron sucrose complex. J Med Assoc Thai 2005; 88: 108-109.

16. Momen AK, Meshari A, Nuaim L, et al. Intravenous iron sucrose complex in the treatment of iron deficiency anemia during pregnancy. Reprod Biol 1996; 69: 121-124.

17. Giannoulis C, Daniilidis A, Tantanasis T, Dinas K, Tzafettas J. Intravenous administration of iron sucrose for treating anemia in postpartum women, HIPPOKRATIA 2009, 13, 1:38-40. 
ORIGINAL ARTICLE

\begin{tabular}{|c|c|c|}
\hline $\begin{array}{c}\text { Maternal Variables } \\
\text { Age (years) }\end{array}$ & $\mathbf{N}=\mathbf{6 0}$ & $\mathbf{\%}$ \\
\hline$<20$ & 1 & 1.67 \\
\hline $20-25$ & 34 & 56.67 \\
\hline $25-30$ & 19 & 31.67 \\
\hline $30-35$ & 4 & 6.67 \\
\hline$>35$ & 2 & 3.33 \\
\hline PARITY & & \\
\hline Primipara & 19 & 63.34 \\
\hline Multipara & 11 & 36.66 \\
\hline
\end{tabular}

TABLE 1: DISTRIBUTION OF STUDY POPULATION ACCORDING TO BASIC CHARACTERISTICS

\begin{tabular}{|c|c|c|c|c|c|c|}
\hline \multirow{2}{*}{$\begin{array}{c}\text { Hemoglobin level } \\
\text { (gm./dl) }\end{array}$} & \multicolumn{3}{|c|}{$\begin{array}{c}\text { Group A (n=30) } \\
\text { intravenous iron }\end{array}$} & \multicolumn{3}{c|}{$\begin{array}{c}\text { Group B (n = 30) } \\
\text { oral iron }\end{array}$} \\
\cline { 2 - 7 } & Day 0 & Day 7 & Day 30 & Day 0 & Day 7 & Day 30 \\
\hline $5.6-6.5$ & 4 & 0 & 0 & 1 & 0 & 0 \\
\hline $6.6-7.5$ & 17 & 0 & 0 & 19 & 1 & 0 \\
\hline $7.6-8.5$ & 9 & 4 & 0 & 10 & 17 & 0 \\
\hline $8.6-9.5$ & 0 & 16 & 0 & 0 & 12 & 0 \\
\hline $9.6-10.5$ & 0 & 10 & 3 & 0 & 0 & 21 \\
\hline $10.6-11.5$ & 0 & 0 & 17 & 0 & 0 & 9 \\
\hline $11.6-12.5$ & 0 & 0 & 10 & 0 & 0 & 0 \\
\hline
\end{tabular}

\begin{tabular}{|l|c|c|c|}
\hline & Before treatment & On day 7 & On day 30 \\
\hline Mean hemoglobin $(\mathrm{gm} . / \mathrm{dl})$ & $7.23 \pm$ SD 0.53 & $9.24 \pm$ SD 0.55 & $11.24 \pm$ SD 0.53 \\
\hline Mean serum ferritin $(\mu \mathrm{g} / \mathrm{l})$ & $11.40 \pm$ SD 0.94 & $40.42 \pm$ SD 7.76 & $49.21 \pm$ SD 3.33 \\
\hline
\end{tabular}

TABLE 3: GROUP A: MEAN VALUES OF BLOOD RESULTS BEFORE AND AFTER INTRAVENOUS IRON TREATMENT

*SD - standard deviation

\begin{tabular}{|r|c|c|c|}
\hline & Before treatment & On day 7 & On day 30 \\
\hline Mean hemoglobin $(\mathrm{gm} . / \mathrm{dl})$ & $7.33 \pm$ SD 0.41 & $7.42 \pm$ SD 0.39 & $10.33 \pm$ SD 0.38 \\
\hline Mean serum ferritin $(\mu \mathrm{g} / \mathrm{l})$ & $11.35 \pm$ SD 0.91 & $14.17 \pm$ SD 1.10 & $15.86 \pm$ SD 2.28 \\
TABLE 4: GROUP B: MEAN VALUES OF BLOOD RESULTS \\
BEFORE AND AFTER ORAL IRON TREATMENT
\end{tabular}




\begin{tabular}{|c|c|c|c|c|}
\hline \multirow[t]{2}{*}{ SIDE EFFECTS } & \multicolumn{2}{|c|}{$\begin{array}{c}\text { Group A }(n=30) \\
\text { Intravenous iron }\end{array}$} & \multicolumn{2}{|c|}{$\begin{array}{c}\text { Group B }(n=30) \\
\text { Oral iron }\end{array}$} \\
\hline & Number & $\%$ & Number & $\%$ \\
\hline 1. Nausea \& vomiting & - & - & 3 & $10 \%$ \\
\hline 2. Constipation & - & - & 5 & $16.67 \%$ \\
\hline 3. Diarrhea & - & - & 1 & $3.33 \%$ \\
\hline 4. Epigastric pain & - & _ & 2 & $6.67 \%$ \\
\hline 5. Rashes & 2 & $6.67 \%$ & _- & - \\
\hline 6. Hypotension & 1 & $3.33 \%$ & - & - \\
\hline 7. Chills & 1 & $3.33 \%$ & - & - \\
\hline 8. Anaphylactic shock & nil & nil & - & - \\
\hline
\end{tabular}

\section{TABLE 5: DISTRIBUTION OF STUDY POPULATION ACCORDING TO SIDE EFFECTS}

\section{AUTHORS:}

1. Samta Gupta

2. Shelly Agarwal

3. Nimmi Chuttani

4. S. S. Gulati

\section{PARTICULARS OF CONTRIBUTORS:}

1. Assistant Professor, Department of Obstetrics \& Gynaecology, School of Medical Sciences and Research, Sharda Hospital, Greater Noida.

2. Assistant Professor, Department of Obstetrics \& Gynaecology, School of Medical Sciences and Research, Sharda Hospital, Greater Noida.

3. Professor, Department of Obstetrics \& Gynaecology, School of Medical Sciences and Research, Sharda Hospital, Greater Noida.
4. Professor, Department of Obstetrics \& Gynaecology, School of Medical Sciences and Research, Sharda Hospital, Greater Noida.

\section{NAME ADDRESS EMAIL ID OF THE CORRESPONDING AUTHOR:}

Dr. Samta Gupta, 01053, ATS Paradiso, Plot No. - GH03, Sector - CHI-4, Greater Noida - 201308.

E-mail: samtagup12@gmail.com

Date of Submission: 12/02/2014. Date of Peer Review: 13/02/2014. Date of Acceptance: 21/02/2014.

Date of Publishing: 04/03/2014. 